\title{
Research on Digital Autonomous Learning Platform
}

\author{
Lunbin Li \\ Computer and Information Engineering \\ Heihe University \\ Heihe, China
}

\author{
Fuyan Zheng \\ Computer and Information Engineering \\ Heihe University \\ Heihe, China
}

\begin{abstract}
In view of the lack of teaching links and students' weak awareness of independent learning, a scientific digital independent learning platform is developed and constructed. According to the software engineering specification, this paper carries out feasibility analysis, requirement analysis, overall design and detailed design of the platform, and finally realizes the platform. Platform is divided into front and back, students can download teaching resources through the front desk, also self-test, timely understanding of self-learning. Teachers manage various kinds of information through the background, such as user information management, self-test topic management, message board management. Practice shows that this platform can fully mobilize the enthusiasm and initiative of students' independent learning, and enhance the teaching effect. It has certain practical value and is worth popularizing.
\end{abstract}

Keywords-autonomous learning; network education; digitization; teaching resources

\section{INTRODUCTION}

With the rapid development of the times, the knowledge explosion and information network and other factors make the national college information education constantly promote and develop, making the way for students to acquire knowledge more abundant ${ }^{[\mathrm{P}}$. The traditional teaching mode is limited in time, space, teachers' level and students' personality ${ }^{[2]}$. It can't satisfy the students' desire for knowledge and exploration at this stage. Therefore, it is necessary to make full use of the convenience, openness and interaction of the network to build a platform for students to study independently. Encouraging students to improve the awareness of self-regulated learning, strengthening the interaction between teachers and students, improving the efficiency and quality of students' learning.

\section{PURPOSE AND SIGNIFICANCE}

The use of information technology will combine network resources with traditional education to stimulate students'interest in Online Autonomous Learning and curiosity. In the process of learning, students find and analyze problems, and discuss with teachers and students to solve problems, and enhance the ability of independent learning and teamwork.

Take network technology as the carrier and students as the main body, combine network technology with modern education $^{[3]}$. The use of network technology to activate and induce the enthusiasm of students to learn, so that students'

Teaching reform of Heihe University, Project number: xjg1729, project name: Construction and application of digital autonomous learning platform; Project number: xjg1725, Project Name: Teaching Reform of computer specialty courses in Colleges and Universities Based on improving programming ability learning state from passive to active, without the pressure of teachers and parents to carry out forced learning. Students can make self-decision, self-choice, self-regulation and selfevaluation and reflection in the process of learning. This not only develops students' potential in learning, but also cultivates students' good learning attitude and habits.

\section{FEASIBILITY ANALYSIS}

Feasibility analysis is to inquire a large number of data and data related to the project before the project development, and prove whether the project has certain development feasibility, mainly through economic feasibility, operational feasibility and technical feasibility of three aspects of analysis ${ }^{[4]}$.

\section{A. Economic Feasibility}

When developing, only one PC machine is needed. After putting into use, it can reduce the consumption of paper resources, bring many direct or indirect benefits to teachers and students, and greatly reduce the waste of labor costs and economic costs. Therefore, the platform is feasible economically.

\section{B. Operational Feasibility}

Through a computer, students can log on to this platform anytime, anywhere, to view and modify personal information, and find the resources they need documents for learning and self-test. After entering the background, teachers can modify their personal information; upload teaching courseware, teaching videos and periodic test questions regularly for students to learn. When the administrator user logs in the background, the information of teachers and students can be modified and added, and the online test questions can be updated regularly. The whole platform is convenient and smooth in operation, so that each user can quickly grasp the use of the platform methods and steps. Therefore, this platform is feasible in operation.

\section{Technical Feasibility}

Using Struts2, Spring, Hibernate framework for development, SSH framework has good scalability, good maintainability, excellent decoupling. The MyEclipse 8.5 compiler is used to maximize the efficiency of the entire application server. The AJAX technology used in the front page realizes the interactive transmission between data, reduces the waiting time of users, and maintains the integrity of communication data with the server without refreshing the 
entire page ${ }^{[5]}$. This prevents students from having to worry about not sending the changed information for a long time when they are testing online, which leads to the impact of dropping the line and brings a good user experience. The database uses Mysql, which is widely used in most small and medium-sized websites, and uses the standard SQL database language familiar to the industry. Therefore, the platform is technically feasible.

\section{REQUIREMENT ANALYSIS}

Requirement analysis is a process in which the developer, after in-depth and careful investigation and analysis, accurately understands the specific requirements of users and projects, such as function and performance, and converts the user's nonformal requirements into a complete requirement definition, so as to determine what the system must do ${ }^{[6]}$.

\section{A. Functional Requirement}

Through personal information module, administrators can query and modify my basic information. Through the user management module, the administrator can check or delete the student user information, manually add the teacher user information or delete the leaving teacher information. By announcements management module, administrators can publish regular announcements or delete error notices. By selftesting topic management module, administrators can add or delete students' online test questions. Through the message board management module, administrators can view each student's messages, and delete some of the messages that have nothing to do with learning.

Through courseware management module, teachers can add courseware and delete expired courseware according to resource classification. Through the teaching video management module, teachers can upload teaching video matching the courseware for students to learn and delete outdated or old video. Through the test question management module, teachers can upload the stage test questions matching the teaching courseware for students to conduct self-test, and then publish the answers.

Through the courseware module, students can classify and search the required courseware and download learning. Through announcement management module, students can check the announcement issued by the college. Through the teaching video module, students can classify and find matching video courseware for online playback learning. Through the examination questions module, students can download the periodic examination questions that teachers upload regularly to match the courseware for students to evaluate their selflearning. Through the online testing module, students can conduct real-time online basic testing on the contents of their study, so that students can understand the current knowledge mastery. Through the message board management module, students encounter difficulties in learning knowledge, through the release of messages to inform administrators.

\section{B. Performance Requirements}

According to the user's demand for this platform, ensure that the platform can be long-term, safe, stable, reliable and efficient operation.

This platform can manage user information, teaching courseware information, teaching video information, message board information completely, comprehensively and uniformly. Background management column and front column correspond one by one to ensure the accuracy and convenience of information management, so that users can accurately obtain all kinds of information they need in this platform.

When the user logs on to the platform to operate, it can complete the access to the database in a very short time, and feedback the results of the operation to the user, with a very high execution. And in case of special circumstances, the popup box will be displayed in time to avoid users waiting for a long time.

Users of different permissions enter their respective operation management interfaces according to different permissions. And each user can only modify their personal information to ensure that the user's personal information security is guaranteed.

\section{OVERALL DESIGN}

\section{A. Function Module Design}

The function module diagram of the digital autonomous learning platform is shown in Fig. 1.

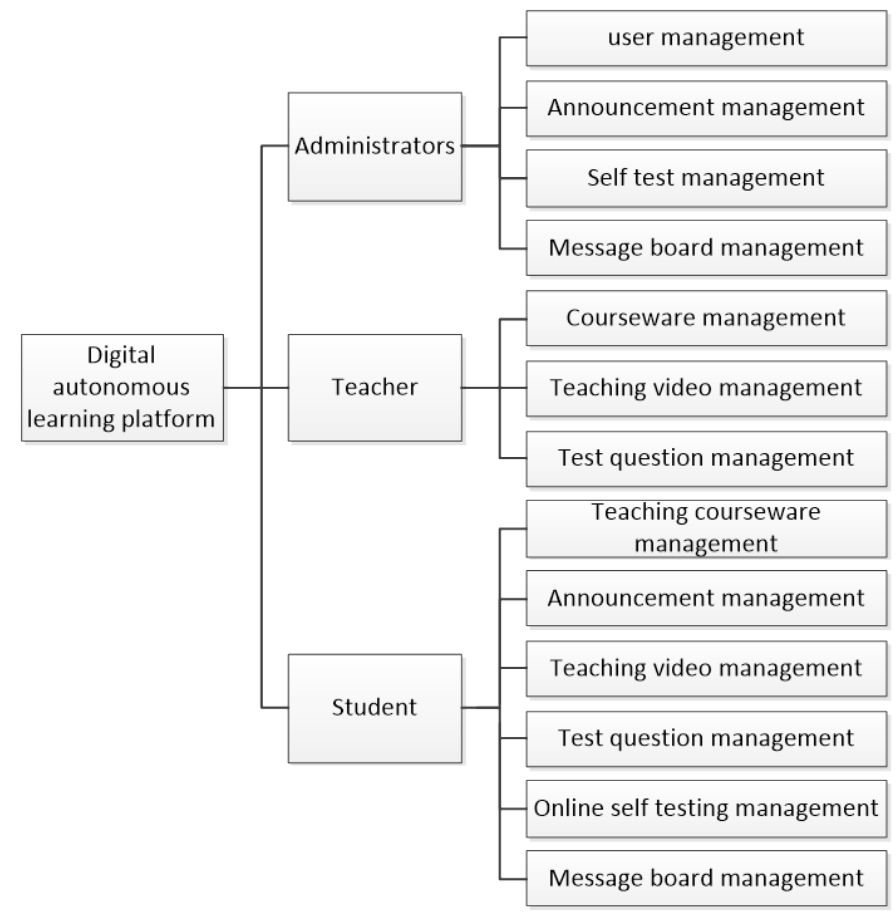

Fig. 1. Function module diagram of digital autonomous learning platform 


\section{B. Database Design}

The conceptual structure design of database is related to the logical structure design, and the relational schema is directly related to the realization of database and the relationship between various objects. Autonomous learning platform includes administrator information, teacher information, student information, teaching courseware information, teaching video information, announcement information, message board information, stage examination questions information, self-test questions information and other entities and their attributes. The administrator user entity includes the properties of the entity's primary key ID, administrator user name, administrator password, and so on. Teacher user entities include entity primary key ID, teacher number, teacher name, teacher gender, teacher age, teacher login name, teacher login password and other attributes. Student user entities include entity primary key ID, student number, student name, student gender, student age, student login password, audit status and other attributes. The entity of teaching courseware includes the attributes of entity primary key ID, name, attachment, attachment original name, time, category and so on. The announcement entity includes properties such as primary key ID, title, content, format, and so on. Message board entities include entity key ID, title, content, format, message and other attributes. Teaching video entity includes entity primary key ID, video name, video profile, category, attachment original name, time and other attributes. The entity of the periodic examination questions includes the attributes of the entity's primary key ID, the title of the examination questions, the appendix, the original name of the appendix and the time. The entity of self-test questions includes the attributes of entity primary key ID, title, option a, option b, option c, option d, answer, score and so on.

\section{DETAILED DESIGN AND IMPLEMENTATION}

\section{A. Front Page Design}

The platform adopts the standard four-grid layout in the design of the main front page, the logo navigation bar at the top of the header, the notice bar on the left of the left of the header, the right-side interface display and the copyright at the bottom of the footer. The logo is placed in the middle of the header by clicking the navigation bar below the header, and then the right-side interface will display each column. The corresponding page. Student users can simply understand the specific functions of the platform in the front page, jump to the main page after registering the account, and then browse the page they need in the main page.

\section{B. Design of User Information Management Module}

This module is used to display basic information of users. Administrator users can add and delete the teacher user information, and examine and delete the student user information. It is convenient for platform administrators to statistics the information of all users. When teachers and students enter the page, they can only view and modify their personal information.

\section{Design of Announcement Management Module}

This module is used to display the announcement information, including title, content, time and so on. Administrators in this module to manage all the announcement information, you can publish the latest announcement or delete the error announcement. When the administrator releases the latest announcement, students can see the latest announcement issued by the administrator in the front login page.

\section{Module Design of Self Test Questions}

The module is used to display various information of online self-test questions, including questions, options, answers, scores and other information. In this page, administrators can click the Add button to add self-test questions using the add () method to manage the self-test questions, and when the questions appear to be wrong, click the delete button to delete the corresponding errors in the database by delete () method. Students can view the real-time online test questions added by the administrator on this page. Students can select the topics according to what they have learned and conduct selfassessment questions, so as to realize the real-time evaluation of the progress and achievements of self-learning.

\section{E. Interface Design of Courseware Management Module}

This module is used to display all courseware information on this platform. Teachers can upload or delete the courseware according to the category, and students can choose the courseware they need according to the category. The teacher clicks the Add button to enter the upload. JSP page. When the information is input, the data is uploaded to the server through the DOM post method of the form from. The server confirms whether to use the add () method to write the courseware data to the database according to the complete information, and then stores the attachment in the corresponding folder.

\section{F. Design of Teaching Video Management Module}

The module is used to display instructional video information matching courseware. Teachers go to the page, add teaching video by clicking the add button, click the delete button to delete the expired video; students enter the page, you can watch teaching video online or download the required video.

\section{G. Design of Test Management Module}

The module is used to display the examination questions information matching with the courseware. When the student learns independently for a period of time, the teacher uploads the periodic examination question document for the student to download the test. When the test question expires, the teacher can delete the test question. Students go to the page, search through the category, find the required test document, and click the attachment. doc to download the document.

\section{H. Design of Message Board Management Module}

This module is mainly used to display students' message. Administrators can view and delete messages, and students can only post messages. Administrators can click the delete button to delete messages that have nothing to do with teaching, and 
students can click on the page to post some difficult knowledge or useful suggestions in their study.

\section{APPLICATION OF PLATFORM}

With the joint efforts of the teachers and students majoring in computer science and technology, the self-regulated learning platform has been put into operation in this semester. Each teacher is required to plan his or her own teaching resources, such as syllabus, video, test questions, etc. At present, ASP. NET programming, C language programming, Java EE development, software engineering, data structure and other courses teaching resources have been published, by students love. Each teacher is required to reply to students' messages on the platform in time, so that the platform can truly serve as a bridge and link between teachers and students. In addition to the videos of the courses, teachers are required to publish periodically the phased test questions on the platform, use automatic and manual review mechanisms, and track each student's test scores. Students can preview the knowledge and skills that teachers are prepared to explain in advance through the platform of course video learning. The interaction between teachers and students has been greatly improved, and the teaching effect has been greatly improved. The speed and correctness of students' doing exercises and experiments after class reflects that students have fully understood and mastered the knowledge they have learned. Students' desire for new knowledge and skills can be seen in their expectation of asking teachers when to renew teaching resources. These are the results that teachers, schools, parents and society all want to see. This is a successful expression of the platform for independent learning.

\section{CONCLUSION}

This paper designs and implements a platform for independent learning and free communication. Struts2, Spring, Hibernate are used as the development framework and MySQL is used as the database. The platform is divided into foreground and background. The foreground is mainly used by students, including personal information, teaching courseware, teaching video, examination questions, online self-test, message board and other modules. Backstage users are divided into teachers and administrators, administrators backstage includes personal information, teacher management, student management, announcement management, message board management, online test questions management module; teachers backstage includes personal information, teaching courseware management, lesson video management, stage test questions management module.

The biggest highlight of this platform is the realization of the resource search module. Fuzzy inquiry is adopted, and the teaching courseware information database, teaching video information database and the periodic examination question information database are combined. When students search for resources, they only need to input part of the resource keyword information, they can use this kind of teaching courseware. Teaching video and periodical examination questions are inquired.

From the application effect of the digital self-regulated learning platform, it can be seen that students not only learn the knowledge and skills required by the course, but also build up their own confidence in learning, strengthen their interest in learning new knowledge and skills, and ensure that they can meet the needs of the future employment market. Through this platform, students' awareness of self-regulated learning is enhanced, and communication and interaction between teachers and students are strengthened, thus improving the efficiency and quality of students' learning.

\section{REFERENCES}

[1] Guotao Zhao, Resources Construction and Applied Research of College English Online Autonomous Learning Platform. Computer Knowledge and Technology, 2017. (In Chinese)

[2] Caixia Chen, Micro teaching design mode under MOOC environment. Software guide, 2016. (In Chinese)

[3] Yingjian Kang, Self learning system design based on Android platform. information and computer (theoretical version), 2018. (In Chinese)

[4] Wei Feng, Research on the construction of student autonomy learning network platform. Neijiang science and technology, 2018. (In Chinese)

[5] Mi Zou, Autonomous learning platform for open computer experiment teaching. Electronic production, 2018. (In Chinese)

[6] Yuan Yuan, Autonomous learning of College English under the network background of digital age. Campus English, 2018. (In Chinese) 